\title{
ADAPTIVE LEARNING AND ASSESSMENT: FROM THE TEACHERS' PERSPECTIVE
}

\author{
A. Pfeiffer ${ }^{1,2,3,4}$, S. Bezzina ${ }^{2}$, A. Dingli ${ }^{3}$, T. Wernbacher ${ }^{1}$, N. Denk ${ }^{1}$, \\ M. Fleischhacker ${ }^{1,4}$ \\ ${ }^{1}$ Donau University Krems (AUSTRIA) \\ ${ }^{2} B \& P$ Emerging Technologies Consultancy Lab Ltd (MALTA) \\ ${ }^{3}$ University of Malta (MALTA) \\ ${ }^{4}$ Bildungsdirektion Wien (AUSTRIA)
}

\begin{abstract}
Digital technologies have changed and continue to shape the way students interact with learning material, both in traditional and informal education. Adaptive learning methodologies offer an interesting avenue for personalized learning, whereas every individual student is presented with tailormade content, specifically based on the distinct strengths, weaknesses, goals and engagement patterns of the learner. This is intended to consolidate knowledge and ensure that learning progresses at the right time and pace. Underpinning such computer-mediated interventions, one might find simple logic, allowing the content to be adapted after short intermediate tests, up to more complex Artificial Intelligence (AI) methods, which for example, in the realm of serious games, take on the role of the teacher whom facilitates the appropriate learning experience. Such an approach is an interesting and well-meaning methodology that requires additional research and consequently should be developed further, both in terms of the supporting technology and pedagogy. For instance, with regard to the latter, the role of the teachers (and educators in general), in self-directed learning of students whilst utilizing adaptive educational applications is to be investigated. This will allow teachers to take on the role of learning companions and subsequently better estimate the student's progress and facilitate the overall learning experience. In this paper, the authors critically analyse the role of adaptive learning methodologies from the teacher's perspective and extend this notion not only to support the learning experience itself, but also to assess it, particularly in formative and embedded ways. Furthermore, the authors take a glimpse at the future, where in a few years' time, the assessment of a teacher (through standardized testing or otherwise), will no longer be the decisive factor affecting and/or shaping the career path of a child or young adult. As such, this paper takes an explorative approach to identify the current state of play amongst educators, their expectations and fears regarding adaptive learning and assessment, through a mixed methods approach involving an online survey, followed by a focus group discussion with experts in the field.
\end{abstract}

Keywords: adaptive learning, adaptive assessment, artificial intelligence.

\section{INTRODUCTION}

Digital tools offer an exciting platform for instructional design and assessment practices, including a wide variety of assessment methods and formats to assist teachers in their pedagogical endeavors. This has changed and continues to shape the way students interact with learning material, both in traditional and informal education. Over the years and rapid development in educational technology, adaptive learning methodologies have come to the forefront as an exciting avenue for customized learning, whereby every student is provided with tailormade content, precisely and distinctively focused on the strengths, limitations, priorities and interaction patterns of the individual learner.

In this paper, the authors discuss the notion and application of adaptive learning and assessment, from the teachers' perspective, with a focus on the awareness, impact and future of such an approach in education. As such, this paper takes an explorative approach to identify the current state of play amongst educators, their expectations and fears, through a mixed methods methodology involving an online survey, followed by a focus group discussion with experts in the field.

\section{ADAPTIVE LEARNING AND ASSESSMENT}

Adaptive learning, or the automated, dynamic and interactive process of delivering digital learning material "in which the learner's interaction with previous content determines (at least in part) the nature 
of materials delivered subsequently" [1], has been identified as a possible solution for transforming education [2]. The ubiquity of digital technologies and the advent of the internet has extended the notion of adaptive learning outside the formal classroom. Today, a number of adaptive learning tools are also accessible to teachers and students alike, whereas teaching, learning and assessment become heavily personalized in view of a customized educational experience.

An adaptive digital learning and assessment environment is capable of tracking learners' behaviors, analyzing and interpreting these based on domain and user-specific patterns, predicting learner individual requirements and expectations and properly output this data according to comprehensive instructional models [3]. The resulting information is relayed back to the student and teacher, who can in turn act upon such data to improve the educational experience. In this sense, computer-based learning systems have been researched since the 1950's [4]. Artificial Intelligence (AI) has been applied to education in order to improve teaching, learning and assessment activities and to meet the learning needs of individual students. In the field of Artificial Intelligence in Education (AIED), a number of theoretical and practical underpinnings have made their way to the classroom in an attempt to close in on the level of human one-on-one interaction experienced in traditional educational environments [5]. Typically, this involves students reinforcing already covered ideas and also exploring new concepts by solving problems that are based on domain-level knowledge, in subjects such as Mathematics or Science. An Al-enabled adaptive learning and assessment system would then use appropriate algorithms to modify in real-time the learning settings in order to accommodate variations for each student.

From a pedagogical perspective, this implies that rather than a generic and static one-size-fits-all learning and assessment model, teachers and students are being presented with an inclusive and personal approach to both learning and assessment. Such formative and embedded methodology, underpinned by instructional scaffolding, allows for greater agency and personalization [6]. This is due to the capability of the educational environment to respond to the needs of the individual learners through targeted and individual feedback, which is received just-in-time and/or on-demand. Students are thus able to self-assess and self-regulate their learning (even during assessment activities) and effectively close the gap between their present and required achievements [7]. Consequently, teachers and students switch from dependent to autonomous instructional models and strategies, in a truly assessment for learning environment.

\section{METHODOLOGY}

The research question that has been identified and consequently guided the authors explorative approach in this study was: What is the role of adaptive learning and assessment in the students' educational experience? This was exclusively aimed at educators, as the authors were interested in the teachers' perspectives on the role of adaptive learning and assessment in terms of the students' overall educational experience.

To achieve their research goal, the authors designed and administered a survey, consisting of 9 questions, each based on a five-point Likert scale, to 64 participants (Table 1). Most of the participants $(45 \%)$ work in an adult education context (University and Adult Education).

Table 1. Survey participants.

\begin{tabular}{l|c}
\hline \hline & Number of participants \\
\hline Pre-school & 0 \\
\hline Elementary School & 5 \\
\hline Middle School & 9 \\
\hline High School & 6 \\
\hline College & 11 \\
\hline University & 14 \\
\hline Adult Education & 15 \\
\hline Not an Educator & 4 \\
\hline \hline
\end{tabular}

Furthermore, the authors organized a focus group with 4 experts in the field of adaptive learning to complement and critically analyze the survey responses. The core discussion revolved around the key 
aspects of adaptivity in the learning and assessment processes. Table 2 details the gender and respective background for each focus group participant.

Table 2. Focus group participants.

\begin{tabular}{c|c|c}
\hline \hline Expert ID & Gender & Profession \\
\hline E1 & female & educator (College) \\
\hline E2 & male & Al scientist \\
\hline E3 & male & learning technologist \\
\hline E4 & female & e-learning designer \\
\hline \hline
\end{tabular}

The realization of the focus group is based on the method of the problem-centered interview [8], whilst the evaluation of the key statements [9] was conducted with regard to content-analyses. This problemcentered approach is characterized by the orientation towards a socially relevant problem (in this case the concept of adaptivity in learning and assessment) and the organization of the cognition or learning process (pre-interpretation). As such, the interviewer uses the previous knowledge of objective (in this case the knowledge gained through desk research) in order to understand the interviewees' explications and ask questions or demands oriented towards the problem. Parallel to the production of broad and differentiated data material, the interviewer works on the interpretation of the subjective view of the interviewees opinions and refines this in view of the research problem. In the content analysis, in addition to the formation of categories, in this case securing common themes on adaptive learning and assessment, the authors have compacted the results of the focus group in the form of core statements.

\section{RESULTS}

The results of the survey questions and focus group, grouped by identified categories, are presented in the following subsections.

\subsection{Awareness}

The survey started off with the respondents' awareness of and familiarity with the term 'adaptive learning'. The weighted average registered from all respondents was an above-average value (3.68 / 5). Thus, it can be assumed that the term has already been heard, but an exact definition was not yet widely known or acknowledged. The authors provided the following Wikipedia definition for 'adaptive learning' to guide the survey respondents using clear terms in subsequent questions.

Adaptive learning, also known as adaptive teaching, is an educational method which uses computer algorithms to orchestrate the interaction with the learner and deliver customized resources and learning activities to address the unique needs of each learner.

E1 strongly agreed with this result as the concept of adaptivity has been largely left unexamined throughout the years (both during pre- and in-service teachers' training). E3 confirmed that most teachers would shy away from adaptive learning as in their own viewpoints, this would necessitate of a solid technological background, which most would not consider themselves to possess. E2 corroborated such instances, whereas the whole notion and outsider perspectives on Al and Al scientists is underpinned by a schism, based on preconceived highly specialized knowledge or technological expertise. Although such knowledge and experience in ICT is a pre-requisite, most educators would only be dealing with front end dashboard and administration, which requires little to no technological training.

\subsection{Impact}

The next block of survey questions focused on the actual or perceived impact of adaptivity on learning and assessment. The individual weighted averages for each question registered from all respondents are shown in Table 3. 
Table 3. Impact of adaptivity on learning and assessment.

\begin{tabular}{l|c}
\hline \multicolumn{1}{c|}{ Question } & Score (out of 5) \\
\hline Improvement in face-to-face learning and assessment experience & 4.13 \\
\hline Improvement in e-learning or distance learning and assessment experience & 4.05 \\
\hline A fairer learning and assessment experience & 3.93 \\
\hline A better personalized learning and assessment experience & 3.98 \\
\hline \hline
\end{tabular}

It is very evident that the survey respondents believe that adaptivity has a positive (potential) impact on learning and assessment; in both face-to-face and distance education contexts and in terms of fairness and personalized learning and assessment experience. E1 explained that this is due to the unprecedented power, now in the hands of teachers, to customize learning according to the strengths and needs of their individual students. Through such a formative and embedded approach, teachers have the ability not just to differentiate, but personalize content, process and product for both learning and assessment.

Amongst others, E3 advocated the use of adaptive assessment to meet the strengths and work on the needs of individual students, based on their performance on previous evaluation items. Adaptive assessments are normally underpinned by the Item Response Theory (IRT), which is driving changes in the field of digital assessment. IRT utilizes both the examinee ability estimates and item difficulty estimates to compare the difficulty of the test items. E4 further explained how digital adaptive assessment can administer different items to the right student at any point during the test. This creates both a fairer approach to assessment and also a more engaging one. E2 reported that such approaches are today augmented through Al, specially through machine learning algorithms which involve the gathering and storing of a rich collection of information on each individual student, and turning it into a standardized knowledge base involving different data points. This enables teachers to have a deeper understanding of how learning is changing over time for each student.

\subsection{Future}

The last questions on the survey focused on the future trends of adaptive learning and assessment. The individual weighted averages for each question registered from all respondents are shown in Table 4.

Table 4. Future trends of adaptive learning and assessment.

\begin{tabular}{l|c}
\hline \hline \multicolumn{1}{c|}{ Question } & Score (out of 5) \\
\hline Impact of COVID-19 on adaptive learning and assessment & 3.66 \\
\hline $\begin{array}{l}\text { Impact of COVID-19 on applications of adaptive learning and assessment } \\
\text { (for example in game-based learning) }\end{array}$ & 3.29 \\
\hline More awareness on adaptive learning and assessment is required & 4.02 \\
\hline
\end{tabular}

Survey respondents agree that COVID-19 has shed light on what adaptive learning and assessment means and (although to a less extent) its application through various pedagogies (like game-based learning). However, from the perspective of educators, more awareness on adaptive learning and assessment is required. E3 and E4 both reported that their work has drastically intensified during the COVID-19 time, especially during school closures and country lockdowns. Although most of this involved technology-related problems (for instance on how to upload an assignment on Microsoft Teams or how to connect through Zoom), others looked into personalized learning in online educational environments. Although this was mostly a rare request from the educators, E1 believes that this can only improve through time as teachers come to grips with and in which ways technology can improve their teaching, both in-class and at a distance. In fact, E2 corroborated this by mentioning various in which Al can radically transform education, such as in the predictive analysis of students' performance and process efficiency (automated grading and targeted feedback). 


\section{CONCLUSIONS}

This paper, underpinned by an assessment for learning philosophy, contributes interesting insights to the body of knowledge and practice in the fields of Education and Artificial Intelligence. More than a pedagogical novelty, the arguments presented in the paper are aimed at establishing the status quo with regard to the notion of adaptivity and its impact on learning and assessment, from the viewpoint of educators and corroborated by experts in the field. Broadly categorised under three main themes, namely (i) awareness (ii) impact and (iii) future, the arguments presented are aimed at potentially informing and guiding future research and practice in the respective areas.

\section{REFERENCES}

[1] P. Kerr, "Adaptive learning," Elt Journal, vol. 70, no 1, pp.88-93, 2016.

[2] D. Johnson and D. Samora, "The potential transformation of higher education through computerbased adaptive learning systems," Global Education Journal, vol. 1, 2016.

[3] K. Colchester, H. Hagras, D. Alghazzawi and G. Aldabbagh,"A survey of artificial intelligence techniques employed for adaptive educational systems within e-learning platforms," Journal of Artificial Intelligence and Soft Computing Research, vol. 7, no 1, pp.47-64, 2017.

[4] M. L. How and W. L. D. Hung, "Educational Stakeholders' Independent Evaluation of an Artificial Intelligence-Enabled Adaptive Learning System Using Bayesian Network Predictive Simulations," Education Sciences, vol. 9, no. 2, pp.110, 2019.

[5] K. VanLehn, "The relative effectiveness of human tutoring, intelligent tutoring systems, and other tutoring systems," Educ. Psychology, vol. 46, pp.197-221, 2011.

[6] M. Zanker, L. Rook and D. Jannach, "Measuring the impact of online personalisation: Past, present and future," International Journal of Human-Computer Studies, vol. 131, pp.160-168, 2019.

[7] D. Hooshyar, M. Pedaste, K. Saks, Ä. Leijen, E. Bardone and M. Wang, "Open learner models in supporting self-regulated learning in higher education: A systematic literature review," Computers \& Education, vol. 154, pp. 103878, 2020.

[8] A. Witzel, "Das problemzentrierte Interview," Qualitative Forschung in der Psychologie, pp. 227255, 1985.

[9] P. Mayring, Qualitative Inhaltsanalyse; Grundlagen und Techniken. Beltz Verlag, Weinheim, Basel, 2010. 